\title{
(Ovo-)viviparity in the darkling beetle, Alegoria castelnaui (Tenebrioninae: Ulomini), from Guadeloupe
}

\author{
Anne Marie DUTRILlaUX, Dominique PLUOT-SigWALT and Bernard DUTRILlaUX
}

\author{
UMR 7205 CNRS/MNHN, OSEB, Département Systématique et Evolution, Muséum National d'Histoire Naturelle, CP32,
} 16, rue Buffon, 75005 Paris, France; e-mail: bdutrill@mnhn.fr

Key words. Coleoptera, Tenebrionidae, Ulomini, Alegoria castelnaui, Guadeloupe, chromosomes, (ovo-)viviparity

\begin{abstract}
In the course of cytogenetic studies on Alegoria castelnaui Fleutiaux \& Sallé 1889 (Coleoptera: Tenebrionidae: Tenebrioninae: Ulomini) from Guadeloupe, a number of adult specimens were dissected. A larva was found in the abdomens of almost all of the females. The karyotype, 20,XX / 20,X $\mathrm{y}_{\mathrm{p}}$, and the presence of heterochromatin at multiple chromosomal locations, of the larvae and adults were similar, which excludes parasitism and indicates viviparous reproduction. The adverse habitat of the adults, i.e., putrid and fermenting pseudo-stems of banana trees rather than geo-climatic conditions, may explain the occurrence of viviparity in this species. This is the first example of (ovo-)viviparity in the Ulomini tribe and among New World Tenebrionidae. A. castelnaui is regularly collected on banana trees infested with the weevil Cosmopolites sordidus Germar, 1824, a major pest of banana trees around the word. The coexistence of these two species on banana trees may be coincidental but another Ulomini species, Eutochia pulla Erichson 1843, is described as an egg predator of C. sordidus in Africa and therefore, A. castelnaui could also be a predator of this pest.
\end{abstract}

\section{INTRODUCTION}

Oviparity is the common mode of reproduction in Coleoptera, with other modes such as viviparity (or ovoviviparity) exceptional. The first descriptions of viviparity in species belonging to Staphylinidae and Chrysomelidae were published in the middle of the $19^{\text {th }}$ century (Schiödte, 1853, 1856; Perroud, 1855). Sixty years later, a quite complex mode of reproduction, including viviparity, was described in Micromalthus debilis Leconte (Micromalthidae) (Barber, 1913; Peyerimhoff, 1913). In 1978 , viviparity was reported in tenebrionid beetles from South Africa (Tschinkel, 1978), and latter in carabid beetles (Liebherr \& Kavanaugh, 1985). Additional observations increased the number of (ovo-) viviparous species, as defined by Hagan (1951), to about 50 species of Chrysomelidae, principally Chrysomelini (Bontems, 1984) and 16 Tenebrionidae (Iwan, 2000), all belonging to the Pedinini (Bouchard et al., 2005). At the level of the order Coleoptera, the occurrence of (ovo-)viviparity in one family of Adephaga and four unrelated families of Polyphaga, appears to be quite independent of any systematic classification. It must be kept in mind that the mode of reproduction of many of the 300,000 species of beetles is unknown and therefore (ovo-)viviparity may be less exceptional than it seems.

In the course of a chromosomal study of beetles from Guadeloupe about fifty species were dissected. Usually, only males were dissected, but both sexes were dissected when there was little or no sexual dimorphism, as is often the case in species of Tenebrionidae, such as Alegoria castelnaui Fleutiaux \& Sallé, 1889 (Tenebrioninae: Ulomini). The presence of larvae in the abdomens of a few specimens of this species initially suggested the occur- rence of a parasitism, but it rapidly became apparent that this phenomenon was restricted to females. Further analyses revealed that the larvae were only found in females. In this study, chromosome preparations of tissue from both larvae and adults revealed that they belong to the same species, and thus, demonstrated a viviparous reproduction. Female genital tract was also examined for possible particular anatomical characters associated with viviparous reproduction.

\section{MATERIAL AND METHODS}

Adults were collected from decaying banana tree pseudostems at three localities on Guadeloupe (Basse-Terre): Plateau Palmiste $\left(16^{\circ} 01^{\prime} \mathrm{N}, 61^{\circ} 40^{\prime} \mathrm{W}\right)$, near Sainte-Marie $\left(16^{\circ} 06^{\prime} \mathrm{N}\right.$, $\left.61^{\circ} 38^{\prime} \mathrm{W}\right)$ and Acomat waterfall $\left(16^{\circ} 15^{\prime} \mathrm{N}, 61^{\circ} 45^{\prime} \mathrm{W}\right)$. In March 2007, eight specimens were used for chromosome studies. Four males were dissected to obtain dividing cells and establish the karyotype following the usual methods (Dutrillaux et al., 2006, 2007). Briefly, testicular follicles were placed in an aqueous solution of $0.88 \mathrm{M} \mathrm{KCl}$ for $15 \mathrm{~min}$ at room temperature. They were then transferred into a micro-centrifuge tube (VWR International SAS, code 211-0033, Strasbourg, France) containing $0.5 \mathrm{ml}$ of $0.55 \mathrm{M} \mathrm{KCl}$ solution, where they were squashed and suspended using a piston (VWR, code 045420) of the same internal diameter as the tube. The volume of $0.55 \mathrm{M} \mathrm{KCl}$ was then increased to $1.5 \mathrm{ml}$. After $10 \mathrm{~min}$, the tubes were centrifuged for $5 \mathrm{~min}$ at $800 \mathrm{~g}$. The supernatant was removed and replaced with Carnoy I fixative in which the cells were suspended and left for at least $30 \mathrm{~min}$. After one change of fixative, the cells were spread on wet, cold slides or kept for a few days before use. Slides were stained with Giemsa, photographed and C-banded, according to Angus (1982). In the abdominal cavity of three females, there was a pro-larva and in another female, a small pro-larva and a large egg. One pro-larva was kept alive and later preserved in ethanol. The remaining three pro-larvae were used to obtain cells for the cytogenetic studies. They were 
chopped into fragments in $0.88 \mathrm{M} \mathrm{KCl}$ solution, where they remained for $30 \mathrm{~min}$ after the addition of colcemid. Then, the fragments were transferred into a micro-centrifuge tube, squashed and treated as described above. In December 2007, 25 specimens were collected and dissected. Three of the 13 males were karyotyped. Larvae were again observed in most of the 12 females, and some of them were used for additional cytogenetic studies. Finally, in December 2009, 50 specimens were dissected.

Several individuals were kept in captivity and carefully dissected for anatomical purposes four months later in Paris. They were kept in a $1000 \mathrm{ml}$ plastic container filled with decaying banana leaves at room temperature $\left(20-25^{\circ} \mathrm{C}\right)$ and $100 \%$ humidity. Under these conditions, adults fed, females (if gravid at capture?) larviposited, larvae developed, and moulting and metamorphosis occurred. The expectation is that the new generation will reproduce.

Terminology. It proved difficult to differentiate between a large egg, intra-chorionic embryo or pro-larva and a first instar larva still within the chorion and maternal genital tract. To avoid confusion, any intra-abdominal stage without visible segmentation is called egg and any stage in which segmentation is visible through the chorion and genital tract is called a pro-larva. The term larva is restricted to extra-abdominal stages only.

\section{RESULTS}

\section{Karyotype and demonstration of (ovo-)viviparity}

In the male, the diploid karyotype consists of 20 chromosomes all of which are meta- or sub-metacentric, except for the $\mathrm{Y}$ chromosome, which is punctiform, 20,XY. At diakinesis/metaphase I, the sex chromosomes have a parachute configuration. The meiotic karyotype is thus $2 \mathrm{n}=20, \mathrm{Xy}_{\mathrm{p}}$, which is the case for thousands of species of Coleoptera (Smith \& Virkki, 1978) and most species of Tenebrionidae (Juan \& Petitpierre, 1991) and not a characteristic of a particular species. Fortunately, after C-banding, many chromosomes exhibit clear heterochromatin bands at various intercalary positions, in addition to those in the centromeric regions (Fig. 1). This makes this karyotype characteristic, if not unique. Slight variations in the amount of heterochromatin were observed, which indicates the presence of a polymorphism.

In larvae, there are two types of karyotype: $2 n=20, X Y$ and $2 \mathrm{n}=20, \mathrm{XX}$, corresponding to males and females, respectively. Their chromosomes have the same morphology and C-banding characteristics as those of the adults (Fig. 2). This demonstrates that adults and larvae belong to the same species.

\section{Sex ratio, reproductive status of the females and larval development}

A total of 83 specimens were dissected, among which were 43 males and 40 females. This is not statistically different from a sex ratio of $1 / 1$. Most dissections were performed "in the field" in Guadeloupe and so it was not possible to differentiate unambiguously the components of the female genital tract. Six females were carefully dissected later in our laboratory in Paris.

Each ovary consists of three ovarioles. Usually there is only a single large oocyte (Fig. 6) in one of the ovarioles with the other ovarioles containing very small oocytes that do not reach the vitellogenesis stage. The gross mor-

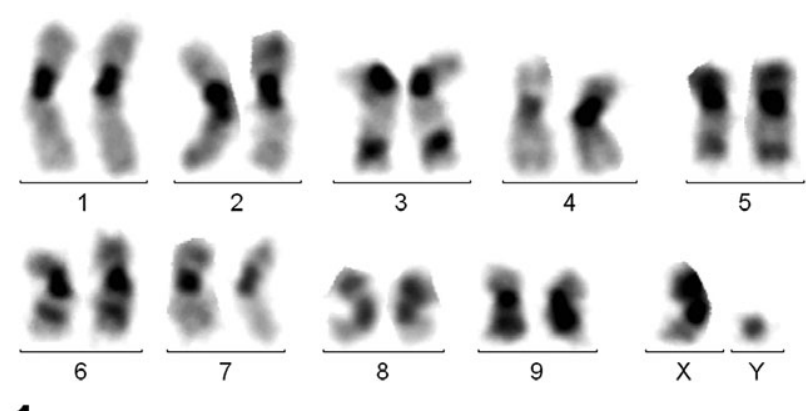

1

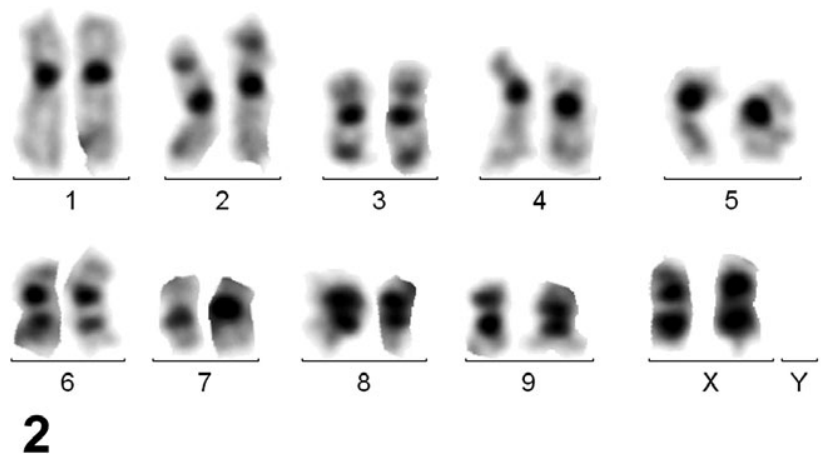

Figs 1-2: Karyotypes of C-banded chromosomes of Alegoria castelnaui. 1 - from a spermatogonium: $2 \mathrm{n}=20, \mathrm{XY}$. The heterochromatin (dark staining) in the short and long arms of many chromosomes is distinctive, which makes this karyotype species-specific. 2 - From a somatic cell of a female larva: $2 \mathrm{n}=$ $20, X X$, with a distribution of heterochromatin similar to that in Fig. 1.

phology of the female genital tract is similar to that known for other Tenebrionidae, in particular Tenebrio molitor L. (Poels, 1972). It is noticeable, however that the vagina (bursa copulatrix) is richly supplied with tracheae and in non-gravid females there is a remarkably dense and thick network of tracheae and tracheoles around the non-swollen bursa copulatrix. Three out of the 32 females that were dissected in Guadeloupe had only small ovarioles. One of them was a young imago (with a brown instead of black cuticle) and apparently immature. One female had a single large ovoid egg. Two females had one large and one small egg. The large egg was at least $4 \mathrm{~mm}$ long and $1 \mathrm{~mm}$ in diameter, and still within the vitellarium. In twenty of the females there was a single pro-larva at different stages of development. Pigmentation of the eye was visible in 14 of the pro-larvae. In four females there was one pro-larva and one large egg (Fig. 3) and in two females two pro-larvae. In all instances, pro-larvae were rectilinear, with the head in an anterior position. The lengths of the largest larvae was about $2 / 3^{\text {rd }}$ that of the adults (Fig. 4). Pro-larvae were enclosed in a double membrane. The external membrane presumably is the genital tract (bursa copulatrix) and the internal one the distended chorion, which was surrounded by many spermatozoa, which are present in the preparations of chromosomes of larvae. In all inseminated females, either gravid or not, a surprisingly high amount of spermatozoa was observed, not only inside the spermatheca but also in 

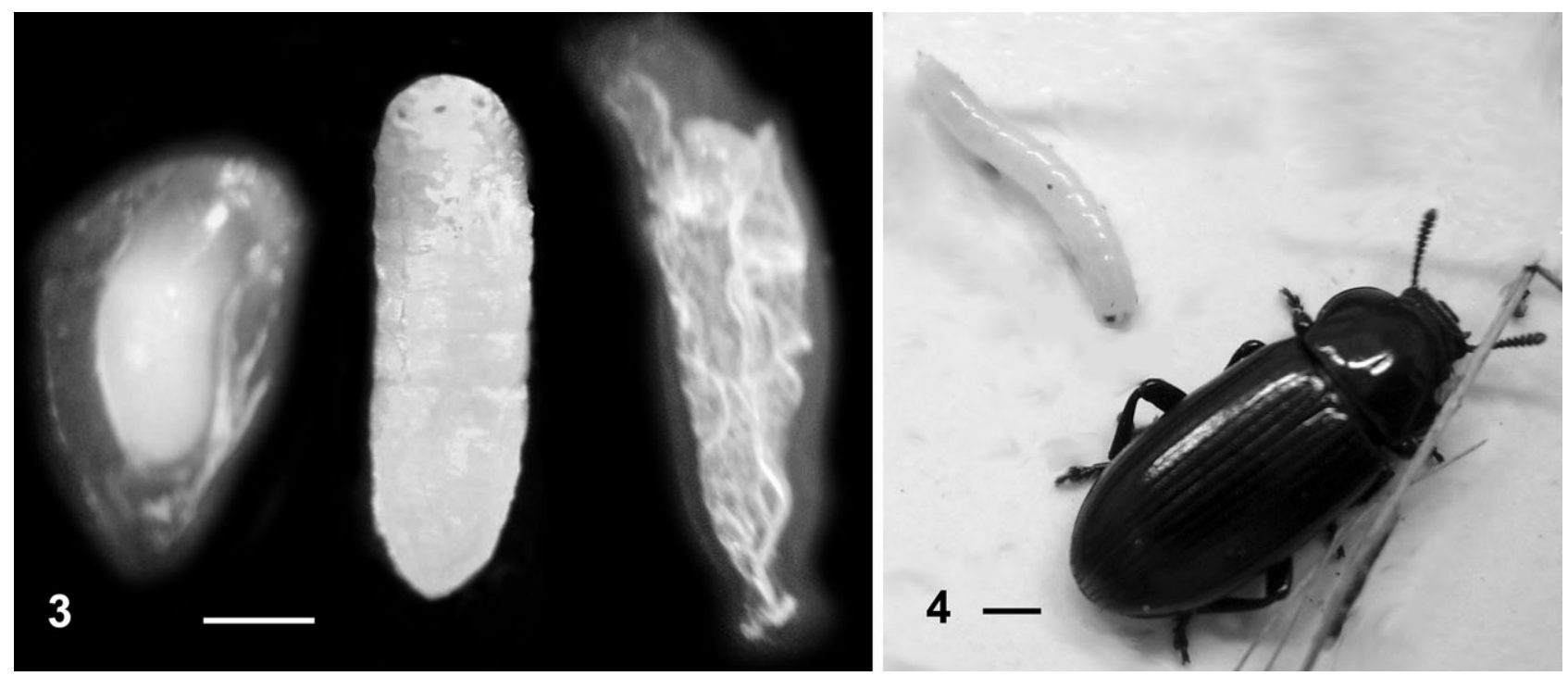

Figs 3-4: A. castelnaui. 3 - Pro-larva (central panel) removed from the bursa copulatrix egg envelop (right) and large egg (left panel), both extracted from the same female. 4 - Larva and adult female from which it was dissected. This larva, which was removed from its enveloping chorion and bursa copulatrix using needles, moulted about $24 \mathrm{~h}$ later and developed into a morphologically normal second instar larva. Scale bars $=1 \mathrm{~mm}$

the lumen of the vagina. The bursae copulatrix containing the larvae is only attached by its posterior extremity to the ovipositor.

The largest pro-larvae were viable and immediately started moving after dissection. One moulted soon after dissection and the second instar larva survived for one week without feeding. Thus, the first instar larval stage is completed or almost so before birth. Unfortunately, the birth of a larva was not observed so it is unknown whether it is a viviparous or ovoviviparous birth.

\section{Other biological data}

At all localities and times of year, adults of $A$. castelnaui were found in decaying pseudo-stems of banana trees. Pigmented larvae were occasionally observed in the close proximity of adults. The density of $A$. castelnaui was frequently high and its abundance paralleled that of the weevil pest, Cosmopolites sordidus Germar, 1824, infesting the same banana trees. Adults, but not larvae, were occasionally found near the corms, but not in direct contact with $C$. sordidus. When last instar larvae of both species were kept together in captivity they all survived and pupated.

\section{DISCUSSION}

A. castelnaui belongs to the Tenebrioninae Latreille, 1802 , one of the 11 sub-families of Tenebrionidae according to Bouchard et al. (2005). It is classified among the Ulomini Blanchard, 1845, a tribe composed of about 340 species and 65 genera (Kim \& Kim, 2004). The genus Alegoria is composed of 12 species and A. castelnaui is the only species present in Guadeloupe. To the best of our knowledge, its (ovo-)viviparous reproduction is the first exemple for the Ulomini, but not the Tenebrioninae, in which there are several viviparous species in South Africa and Madagascar belonging to the Platynotina Mulsant \& Rey, 1853 and Eurynotina Mulsant \&
Rey, 1853 (Iwan, 2000, and references herein) in the tribe Pedinini Eschscholtz, 1829 (Bouchard et al., 2005).

This investigation on the anatomy of $A$. castelnaui, although preliminary, revealed several peculiarities possibly related to (ovo)-viviparity. (1) Reduction of the ovariole number to three, while in other Tenebrionidae each ovary contains from four, as in Tribolium, to 52 ovarioles in Helops (Robertson, 1961). (2) Egg maturation is usually restricted to one ovariole, each ovary functioning alternately. (3) Production of large eggs containing large amounts of yolk. (4) Dense tracheal network around the bursa copulatrix suggesting the need to provide developing embryos with a rich supply of oxygen. (5) Short ovipositor, which is more adapted to laying large eggs than a long ovipositor (Iwan, 2000).

Viviparity in insects is often regarded as a form of parental care and a response to adverse external conditions (Iwan, 2000). It is assumed to be an adaptation to restricted feeding period at high altitudes (Chrysomelinae) or a short rainy season (Pedinini). However, not all viviparous species of Chrysomelinae live at high altitudes (Bontems, 1984). Thus, if external conditions play a major role in the evolution of viviparity then there must be other reasons than a harsh climate. In Guadeloupe, where there is little seasonal variation in the mild climate prevailing there, climate is unlikely to be the causal element. Interestingly, the decaying banana trees, where $A$. castelnaui is found, represent a very particular biotope. The inner tissues of spent pseudo-stems emit a very strong and fetid smell, which seems to consist of alcoholic fermentation and organic putrescence. This may be a harsh environment for insects, especially first instar larvae, which have a thin cuticle. The high proportion of females containing larvae and relative rarity of free living larvae in the pseudo-stems suggest that the external life of larvae is short. 


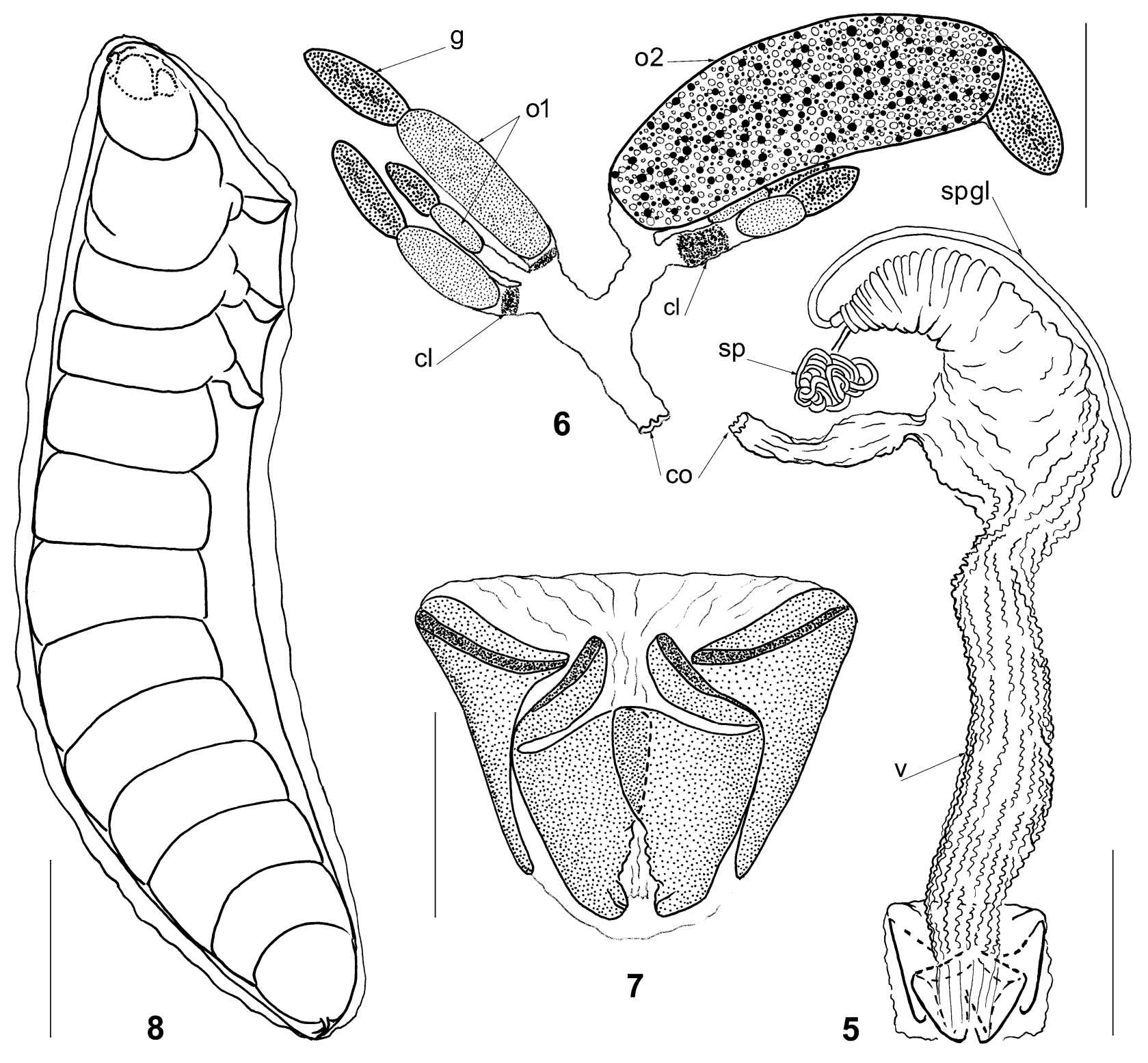

Figs 5-8: A. castelnaui. 5 - Female genital ducts (ectodermal part) after treatment with $\mathrm{KOH}$ (network of tracheae not figured); scale bar: $1 \mathrm{~mm} .6$ - Scheme of the ovaries from a non-pregnant female; scale bar: $1 \mathrm{~mm}$. 7 - Ovipositor, ventral view; scale bar: 0.5 mm. 8 - Late stage embryo still in its egg chorion within the vagina of a female; scale bar: $1 \mathrm{~mm}$. cl - corpus luteum; co - common oviduct; g: germarium; sp - spermatheca; spgl - spermathecal gland; o1 - oocyte at a pre-vitellogenesis stage; o 2 - oocyte at the stage of vitellogenesis; $v$ - vagina (bursa copulatrix).

The diversity of stages of both larvae and adults, from immature to pregnant females, found in decaying pseudostems indicates that they spend their life there. They feed on the petioles surrounding the decomposing centre of the tree and were never found associated with the dry petioles of healthy banana trees. This suggests they feed on decaying tissue, but avoid that which is semi-liquid.

Their coexistence with the curculionid C. sordidus may not be fortuitous. A plausible explanation is that they are just opportunist colonizers of pseudo-stems destroyed by C. sordidus. In Africa, however, at least three species of beetles are predators of C. sordidus (Koppenhöfer, 1993). One belongs to the Hydrophilidae, another to the Histeridae and the third is an egg predator, Eutochia pulla Erichson 1843, which like A. castelnaui belongs to the
Ulomini. If $A$. castelnaui is a predator, it does not eat larvae. Unfortunately, it was not possible to determine whether it eats eggs. Thus, the possible predatory role of A. castelnaui remains purely hypothetical, but because $C$. sordidus is an important pest of banana-trees, it is important to be aware of the possible existence of a predator in neotropical regions.

In conclusion, the karyotype of $A$. castelnaui, though composed of 20 chromosomes as in many Coleoptera, is characterized by the presence of extra-centromeric heterochomatin at several locations. This criterion was used to demonstrate that adult females and their intraabdominal larvae belong to the same species and hence viviparous reproduction. This constitutes the first chromosomal demonstration of viviparous reproduction in 
insects. Adults of $A$. castelnaui live in the decomposing pseudo-stems of banana trees, which may constitute an adverse environment for the development of young larvae and account for viviparity. The presence of $A$. castelnaui and $C$. sordidus in the same pseudo-stems of banana trees suggests that $A$. castelnaui could be antagonist of $C$. sordidus.

ACKNOWLEDGEMENTS. We are grateful to C. Pavis who gave us access to INRA laboratories in Guadeloupe and to reviewers for their constructive comments.

\section{REFERENCES}

Angus R.B. 1982: Separation of two species standing as Helophorus aquaticus (L.) (Coleoptera, Hydrophilidae) by banded chromosome analysis. Syst. Entomol. 7: 275-281.

BARBER H.S. 1913: Observations on the life-history of Micromalthus debilis Lec. Proc. Entomol. Soc. Wash. 15: 31-38.

Bontems C. 1984: La viviparité chez les Chrysomelidae (Col.). Bull. Soc. Entomol. Fr. 89: 973-981.

Bouchard P., Lawrence J.F., Davies A.E. \& Newton A.F. 2005: Synoptic classification of the world Tenebrionidae (Insecta: Coleoptera) with a review of family-group names. Ann. Zool. 55: 499-530.

Dutrillaux A.M., Moulin S. \& Dutrillaux B. 2006: Use of pachytene stage of spermatocytes for karyotypic studies in insects. Chromos. Res. 14: 549-557.

Dutrillaux A.M., Mercier J. \& Dutrillaux B. 2007: X-Y translocation, chromosome compaction, NOR expression and heterochromatin insulation in the Scarabaeid beetle Dynastes hercules hercules. Cytogen. Genome Res. 116: 305-310.

HaGan H.R. 1951: Embryology of the Viviparous Insects. The Ronald Press, New York, 472 pp.

IwAN D. 2000: Ovoviviparity in tenebrionid beetles of the melanocratoid Platinotina (Coleoptera: Tenebrionidae: Platinotini) from Madagascar, with notes on the viviparous beetles. Ann. Zool. 50: 15-25.
Juan C. \& Petitpierre E. 1991: Chromosome numbers and sexdetermining systems in Tenebrionidae (Coleoptera). In Zunino M., Bellès X. \& Blas M. (eds): Advances in Coleopterology. AEC, Barcelona, pp. 167-176.

KIM J.I. \& KIM S.-Y. 2004: Taxonomic review of the tribe Ulomini (Coleoptera, Tenebrionidae) in Korea. Entomol. Res. 34: 277-281.

KoPPENHÖFER A.M. 1993: Egg predators of the banana weevil, Cosmopolites sordidus (Germar) (Col., Curculionidae) in western Kenia. J. Appl. Entomol. 116: 352-357.

LiebherR J.K. \& Kavanaugh D.H. 1985: Ovoviviparity in carabid beetles of the genus Pseudomorpha (Insecta: Coleoptera). J. Nat. Hist. 19: 1079-1086.

Perroud M. B.-P. 1855: Notice sur la viviparité ou l'ovoviviparité des Oreina speciosa Panzer et superba Olivier, avec la description de la larve de cette dernière espèce. Ann. Soc. Linn. Lyon 2: 402-408.

Peyerimhoff P. DE 1913: Paedogénèse et néoténie chez les coléoptères. Bull. Soc. Entomol. Fr. 16: 392-395.

Poels A. 1972: Histophysiologie des voies génitales femelles de Tenebrio molitor L. (Coléoptère: Tenebrionidae). Ann. Soc. $R$. Zool. Belg. 102: 143-169.

Robertson J.G. 1961: Ovariole numbers in Coleoptera. Can. J. Zool. 39: 245-263.

SCHIÖDTE J.M.C. 1853: On some Staphylinidae, found in the nests of thermites. Proc. Zool. Soc. Lond. 21: 101-102.

SCHIÖDTE J.M.C. 1856: Observations sur des staphylins vivipares qui habitent chez les termites. Ann. Sci. Nat. (Zool.) 5: 169-183.

Smith S.G. \& ViRkKi N. 1978: Animal Cytogenetics, Vol. 3. Insecta 5. Coleoptera. Gegrüder Bornstraeger, Berlin, pp. 236-290.

TsCHINKEL W.R. 1978: Ovoviviparity in some tenebrionid beetles. The Coleopt. Bull. 32: 315-317.

Received January 12, 2010; revised and accepted May 10, 2010 